\section{A chance to see the latest innovations}

Carestream Dental is excited to be showcasing some of its new solutions at this year's London Dentistry Show.

Attendees can look forward to seeing the new CS 3800 intraoral scanner in action - the latest in wireless handheld imaging technology that gives practitioners ultimate freedom of movement.

Alongside this, delegates will also have the opportunity to look at the new CS Model+ v5 - a streamlined piece of software that reimagines the orthodontic workflow and that can provide patients with tailored aligner treatment in a snap.

There will also be the opportunity to see Carestream Dental's innovative Sensei Cloud practice management software in action - a future-forward, holistic approach to management with features that benefit the whole team.

For more information, contact Carestream Dental on 08001699692 or visit www.carestreamdental.co.uk.

\title{
Orthodontics practices commit to removing plastic waste
}

Queensway Orthodontics, which has five practices in the North East, has committed to removing and recovering $30-40 \mathrm{~kg}$ of plastic waste.

By joining rePurpose Global's One for One Impact Guarantee Program, Queensway Orthodontics will fund the collection, processing and reuse of 30-40 kg of oceanbound plastic waste for every patient treated with clear, plastic aligners. In effect, Queensway Orthodontics is removing more ocean-bound plastic waste than it uses in its packaging, by reducing its own use of plastic and donating a percentage of every Invisalign purchase to plastic reduction efforts.

Queensway Orthodontics are also working hard to eliminate or reduce plastic waste in the practice wherever possible, with zero-plastic, compostable or recyclable oral health products, including recycling Invisalign clear aligners.

In addition, Queensway Orthodontics - now a Dental CSR Certification - Gold Award company - organised a beach clean-up event to celebrate Plastic Free July and the whole team took part in the exciting initiative. The team collected rubbish from Seaham Beach on Friday 2 July, helping the local community, protecting the beautiful beach and working with The Marine Conservation Society to gather data for the region. The team and their efforts meant they collected 11 bags of rubbish from the beach. www.queenswayorthodontics.co.uk www.dentalcsr.co.uk.

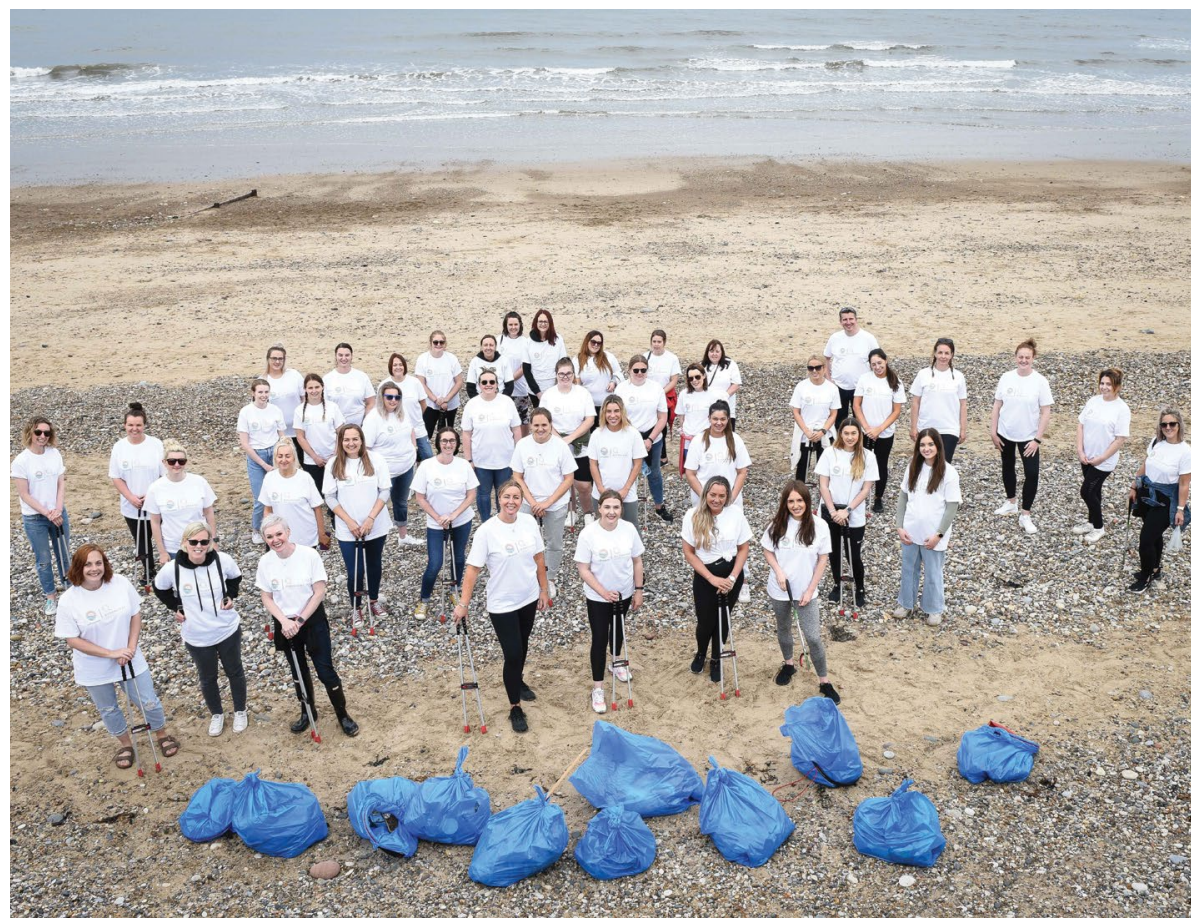

\section{Futureproof your processes}

Dentally will be attending the Dentistry Show London, 17-18 September, at the Olympia.

The list of day-to-day admin tasks can seem endless when running a dental practice - particularly during this crucial recovery period, post-lockdown. With Dentally, you can establish a workflow that will not only futureproof your processes but will give you more time to do what's important: dentistry.

Leveraging the power of the most advanced cloud-based technology, lightning-fast reporting, automated communications and simple patient management can all be achieved seamlessly, allowing you to redirect your focus to providing unbeatable customer experiences, every time.

Interested? Visit Dentally's stand at the Dentistry Show London to see Dentally in action and find out why it is the UK's leading cloud-based dental software, trusted by over 12,000 dental professionals worldwide.

For more information visit: https:// dentally.co/ or call 02038565610 .

\section{Transform your practice from good to great}

For more than 30 years, Software of Excellence has helped thousands of dental professionals transform their practices from good to great. Through a unique combination of cutting-edge software and business insight, SOE's dedicated team of passionate people are here to equip you with everything you need to prepare your practice for the future.

From uncovering new opportunities to maximising the potential already existing within your practice, join Software of Excellence at the London Olympia, 17-18 September, to find out how a tailored practice management solution can support you and your team in not only elevating but retaining staff morale, practice efficiency, patient loyalty and revenue - both now and for the future.

For more information visit: https:// softwareofexcellence.co.uk/ or call 01634 266800. 